Revista de la red interuniversitaria de estudios sobre las

literaturas rioplatenses contemporáneas en Francia

15 | 2016

Un año. Literatura argentina 1969

\title{
El fin de lo nuevo (cineastas, autores, Argentina, 1969)
}

David Oubiña

(2) OpenEdition

Journals

Edición electrónica

URL: http://journals.openedition.org/lirico/2980

DOI: $10.4000 /$ lirico.2980

ISSN: 2262-8339

Editor

Réseau interuniversitaire d'étude des littératures contemporaines du Río de la Plata

\section{Referencia electrónica}

David Oubiña, «El fin de lo nuevo (cineastas, autores, Argentina, 1969) », Cuadernos LIRICO [En línea], 15 | 2016, Puesto en línea el 05 octubre 2016, consultado el 07 mayo 2019. URL : http:// journals.openedition.org/lirico/2980 ; DOI : 10.4000/lirico.2980

Este documento fue generado automáticamente el 7 mayo 2019.

\section{(c) $(1) \odot$}

Cuadernos LIRICO está distribuido bajo una Licencia Creative Commons Atribución-NoComercialSinDerivar 4.0 Internacional. 


\title{
El fin de lo nuevo (cineastas, autores, Argentina, 1969)
}

\author{
David Oubiña
}

\section{I}

1 En 1969, poco antes de empezar a trabajar sobre Los hijos de Fierro, Fernando Solanas cuestiona la adaptación que Torre Nilsson había hecho a partir del libro de José Hernández:

Martín Fierro no es para Nilsson ni para sus fervorosos aduladores el conflicto todavía vigente del pueblo argentino contra la oligarquía, sino la imagen anquilosada de una rebeldía que si ayer tuvo sus razones de ser, encuentra hoy su única opción en lo que se ha dado en llamar en numerosos frentes 'reencuentro nacional'. La noactualización de ese conflicto por parte de Nilsson, la castración del pensamiento de Hernández, que si hoy viviera sería un perseguido más entre tantos perseguidos, es lo que ha permitido que el Sistema reconociera ese film como cosa propia, como instrumento adecuado a su política global. ${ }^{1}$

2 No resulta exagerado pensar que Los hijos de Fierro fue concebido como una respuesta polémica que debatía con Nilsson por el sentido que se le debía asignar al poema de Hernández a fines de los 60. Para Solanas, el protagonista en el film de Nilsson carece de historicidad, como una pieza de museo desprovista de todo conflicto y que nunca interroga al presente. ¿Cómo habría que leer Martín Fierro, cómo actualizar el texto, cómo volverlo contemporáneo? Solanas dirá: como la cifra de un problema social nunca satisfecho que todavía es padecido por los descendientes de ese gaucho en las fábricas, en los campos y en las oficinas del país.

3 Solanas ya ha concluido La hora de los hornos (1966-1968) que, en los años siguientes, se convertirá en el film político más influyente. La película se había estrenado en la Muestra Internacional del Nuevo Cine de Pesaro y había sido un éxito inmediato; pero a mediados de 1969, la proyección en el Festival de Cannes genera un incidente diplomático: molesto por la imagen del país que se muestra en la película, el gobierno argentino se queja ante las autoridades del Festival y pide, a cambio, que se exhiba Invasión, la opera prima de 
Hugo Santiago ${ }^{2}$. Los estilos y las ambiciones de los dos films no podrían ser más diferentes. En contra del conceptualismo político de Solanas, Santiago realiza un film absolutamente formalista. Su trama fantástica -tal como fue entendida en ese momentoparece querer escapar de las determinaciones materiales de la historia. $Y$ ese efecto de ficción atemporal se vuelve más problemático al advertir las influencias del realizador: por un lado, su estilo visual marcado por el ascetismo trascendental de Bresson y, por otro, el guión de Borges y Bioy Casares (que, luego de la revisión efectuada por la revista Contorno, han pasado a ser los ejemplos más conspicuos de una literatura reaccionaria y desentendida de lo real).

Invasión se mantiene fiel al universo modernista, como si no hubiera sido alcanzado por los procesos de desmaterialización tan usuales en los años 60. Mientras La hora de los hornos procura sacar al espectador de su actitud pasiva para fundirse con él en un ritual político, la película de Santiago permanece confinada dentro de las categorías cinematográficas (la idea de obra, de autor, de espectador y de exhibición comercial) más tradicionales. Ante los ojos del cine militante, Santiago representa una continuación y una profundización de los tibios intentos renovadores insinuados por Torre Nilsson y la Generación del 60. Todavía piensa en el cineasta como auteur (según los lineamientos establecidos por la revista Cahiers du cinéma: el creador singular que expresa su cosmovisión a través de la puesta en escena), allí donde Solanas y el Grupo Cine Liberación piensan en el film como un instrumento de concientización colectiva que sólo sirve si conduce a la acción revolucionaria.

\section{II}

5 El mismo año en que La hora de los hornos se exhibe en el Festival de Pesaro, Barthes escribe el célebre ensayo «La muerte del autor» $y$, al año siguiente, Foucault pronuncia su conferencia «¿Qué es un autor?» ante la Sociedad Francesa de Filosofía. En esas intervenciones se ponen en cuestión algunas categorías que habían resultado fundamentales para la interpretación literaria. Básicamente: la intencionalidad del texto en tanto que clave para desentrañar su sentido e, incluso, la figura misma del autor como un pliegue de nuestro discurso que podría fácilmente desaparecer (recuérdese el argumento de Foucaul con su impronta fuertemente beckettiana «qué importa quién habla»). Indudablemente esos axiomas funcionan, para Solanas, como un marco conceptual o como un horizonte de época. De todos modos, es evidente que su interlocutor privilegiado es el cine que, en ese mismo momento, realiza Jean-Luc Godard.

Luego del mayo francés, Godard había rechazado los postulados de la Nouvelle vague y se había propuesto refundar la práctica cinematográfica sobre bases nuevas. Dijo en una entrevista: "Quien dice contenido nuevo debe decir formas nuevas, quien dice formas nuevas debe decir nuevas relaciones entre contenido y forma. De lo contrario, tanto en el cine como en cualquier lucha social, sólo sabe responder de manera antigua a cuestiones completamente nuevas» ${ }^{3}$. A partir del encuentro con Jean-Pierre Gorin (miembro de la Unión de Juventudes Comunistas Marxistas Leninistas), el realizador concibe la idea de un colectivo cinematográfico integrado por militantes de diversas organizaciones maoístas. Esa célula de producción cinematográfica y activismo revolucionario se da a conocer como Grupo Dziga Vertov. Su objetivo es realizar films que provoquen intervenciones críticas en abierta beligerancia con el aparato cultural, social y político: contra la 
burguesía y el revisionismo, por un lado, y contra las formas cinematográficas convencionales, por otro.

7 La estrategia consiste en mostrar y, al mismo tiempo, deconstruir críticamente eso que muestra. Los cineastas producen las imágenes pero, a la vez, las imágenes interrogan a los cineastas sobre su propio funcionamiento y los obligan a replantear los protocolos que deberían sostener a un film político. Viento del Este (Grupo Dziga Vertov, 1969) incluye una breve participación de Glauber Rocha que, parado en un cruce de caminos -con los brazos extendidos, como si fuera un Cristo tropicalista y revolucionario-, canturrea «Divino, Maravilloso» mientras señala las direcciones del cine político: «Hacia allá, está el cine desconocido, el cine de aventura. Hacia aquí, está el cine del tercer mundo; es un cine peligroso, divino y maravilloso». Esta intervención no implica que Viento del Este formule una defensa o un compromiso con el cine del tercer mundo sino que aparece, más bien, como una referencia, una inspiración, un punto de confrontación que la película evalúa intentando definir su propio camino. Godard y Gorin, no usan su film para reflexionar sobre la causa del tercer mundo sino que emplean al tercer mundo para reflexionar sobre su film. La bifurcación de caminos no hace más que expresar la tensión entre dos alternativas, entre dos perspectivas geopolíticas, entre dos modos de entender la función del cine revolucionario. Rocha sólo se integra como una presencia disidente en el film de modo que, en el punto mismo del encuentro, se evidencia el desacuerdo.

8 Al romper con la Nouvelle vague, Godard había abjurado de las nociones de obra y de autor que, ahora, le resultan categorías irremediablemente burguesas y reaccionarias. Rocha, en cambio, traduce la politique des auteurs propuesta por Cahiers du cinéma como método do autor. De esa manera, acentúa su carácter programático y la convierte en un plan de acción revolucionario: en el contexto latinoamericano, el cineasta-autor se define como un intelectual y un militante. Cine de autor, entonces, no en el sentido asignado por el individualismo burgués sino como una vibración comprometida con la historia que, al expresarse, pone en escena toda una lógica social impulsada hacia el cambio. Para el director brasileño, revolucionar el concepto de autor cinematográfico significa no sólo romper con el cine comercial de entretenimiento sino también con el cine más audaz de los países desarrollados. Los autores latinoamericanos y los auteurs europeos pertenecen a dos clases socio-cinematográficas diferentes. Se entiende que un cineasta europeo pretenda destruir el cine y darlo por acabado; pero en Latinoamérica, dirá Rocha, el cine aún está por comenzar. No se puede destruir lo que todavía no existe. Godard acusa a los directores del Cinema novo de hacer películas revisionistas en vez de películas revolucionarias pero, en cierto sentido, Glauber radicaliza las posiciones del propio Godard.

9 Es que, aunque el Grupo Dziga Vertov intenta afirmar un modo de enunciación donde no importa quién habla (y por eso no hay títulos de créditos en sus films), nunca deja de funcionar como una sede extramuros del autor Jean-Luc Godard. Jean-Henri Roger, miembro del grupo en la época de Pravda (1969) y de British Sounds (1969), señaló: «Evidentemente, esas películas son de Godard, de Godard en discusión con otras personas. Eso no quiere decir que la denominación Grupo Dziga Vertov sea un camuflaje. Es su manera de señalar la radicalidad del cambio, de dar cuenta de todas estas discusiones sobre el cine y la política» ${ }^{4}$. La singularidad del cineasta, entonces, no se diluye sino que deviene una forma de identidad expandida. Por eso, para Rocha, Viento del Este es un film políticamente inofensivo. 
Godard -escribió- resume todos los interrogantes del intelectual europeo de hoy en día: ¿vale la pena hacer arte? [...] La cuestión de la utilidad del arte es vieja, pero está de moda y, en el cine, Godard es su propia crisis ambulante. Godard es nuestro Fernando Ezequiel Solanas en Buenos Aires. La verdad, sin embargo, les guste o no a los intelectuales patricios, es que el cine europeo y el americano entraron en un callejón sin salida y sólo es posible hacer cine en los países del tercer mundo. ${ }^{5}$

De manera significativa, Rocha marca sus diferencias incluso con Solanas, porque Solanas se alinea en un continuo con Godard: un cineasta latinoamericano que no ha podido desembarazarse de la herencia cultural europea, aunque se trate de la cultura europea de izquierda.

\section{III}

11 El concepto de Tercer cine, acuñado por Fernando Solanas y Octavio Getino, sintoniza en gran medida con la actitud cuestionadora que proponen Godard y su grupo de cineastas maoístas. Ni el Primer cine (según el modelo industrial de Hollywood) ni el Segundo cine (que intenta una revuelta inútil, acotada por los límites del arte pequeño burgués); frente a esas formas convencionales, la única alternativa válida es un cine desde afuera y en contra del sistema. Eso es el Tercer cine: un cine de descolonización que opone

al cine industrial, un cine artesanal; al cine de individuos, un cine de masas; al cine de autor, un cine de grupos operativos; al cine de desinformación neocolonial, un cine de información; a un cine de evasión, un cine que rescate la verdad; a un cine pasivo, un cine de agresión; a un cine institucionalizado, un cine de guerrillas; a un cine espectáculo, un cine de acto, un cine de acción; a un cine de destrucción, un cine simultáneamente de destrucción y de construcción; a un cine hecho para el hombre viejo, para ellos, un cine a la medida del hombre nuevo: la posibilidad que somos cada uno de nosotros. ${ }^{6}$

Lección de historia política, ensayo de interpretación sociológica, tribuna de provocación y arenga, manual de retórica revolucionaria, panfleto, collage: La hora de los hornos establece los principios de una militancia que pronto será adoptada por los grupos de cineastas más radicalizados. Se trata de una película urgida por la comunicación de un mensaje y cuya máxima aspiración es traducirse en acciones transformadoras. Eso es lo que escriben Solanas y Getino: «Lo que define a un film como militante y revolucionario es la propia práctica del film con su destinatario concreto: aquello que el film desencadena como cosa recuperable en determinado ámbito histórico para el proceso de liberación $»^{7}$. En La hora de los hornos, la figura del autor en tanto que creador individual tiende a diluirse; sin embargo, hay un director y eso está explicitado en los títulos de la película. Igual que en el caso del Grupo Dziga Vertov, Cine Liberación funciona como una caja de resonancia, como una instancia de cotejo, de consejo o de debate, como estructura de legitimación, como contralor o reválida. De modo que el borramiento del autor no responde aquí a esa figura que la retórica clásica ha definido como pluralis modestiae. Porque no se trata de omitir o disminuir la responsabilidad del enunciador singular desdibujando su presencia en un «nosotros» inclusivo ${ }^{8}$. Si no hay una subjetividad individual que se manifiesta en el enunciado de La hora de los hornos, eso se debe a que el discurso de los sucesos se presenta como autoevidente. Los hechos -digamos- hablan por sí solos. Y las estadísticas son la adjetivación más eficiente. Los datos (demográficos, económicos, productivos) indiscutibles, el elaborado sistema de citas legitimadoras, la objetividad de las pruebas históricas, la contundencia de las imágenes y la eficacia de las 
consignas: todo eso convalida un punto de vista que, entonces, deja de ser un punto de vista para convertirse en la única interpretación correcta.

Hay, por supuesto, diferencias entre el counter-cinema del Grupo Dziga Vertov y el Tercer cine del Grupo Cine Liberación. En primer lugar, porque no es lo mismo hacer un cine anti-burgués en Europa que en America Latina: cuando se trata de una oligarquía dependiente, el ataque a las clases dominantes involucra un frente doble porque reclama una discusión sobre el régimen colonial (donde la Teoría de la dependencia ocupa un lugar privilegiado). Pero además, el Grupo Dziga Vertov no exhibe una línea política definida; más bien señala la ausencia de un partido revolucionario en Francia. Y aunque sus integrantes provienen de distintas facciones del maoísmo, sus prácticas militantes participan de nuevas combinaciones en la producción de películas. El Grupo Cine Liberación, en cambio, se adscribe a una política partidaria claramente establecida: de allí parte y a ella contribuye. Se trata de una práctica doctrinaria y aleccionadora que intenta comunicar el mensaje del peronismo revolucionario. Por último -según la afirmación de Gorin-, un film como Tout va bien (Jean-Luc Godard y Jean-Pierre Gorin, 1972) se limita a presentar las contradicciones pero no busca una respuesta concreta. En ese sentido, es un film decepcionante para el gauchisme. No indica el camino a seguir: «es más una máquina de revelado que una profecía»". Frente a esas mismas contradicciones, La hora de los hornos se interroga y se responde: ¿cómo abordar un cine de descolonización?, ¿qué posibilidades existen para una política reformista?, ¿cuál es la única opción que queda para el latinoamericano? Las preguntas nunca son retóricas sino que forman parte de una estrategia de combate y reclaman una contestación programática.

Según Godard y Gorin, el debate político a propósito de la dominación permite interrogar críticamente los modos de representación cinematográficos; según Solanas y Getino se trata, más bien, de experimentar con el lenguaje para construir un argumento ideológico que convenza sobre la necesidad de un proceso de liberación. Allí donde unos piensan en el film como un espacio para discutir sobre las posibilidades del cine en la lucha política, los otros aprovechan los argumentos teóricos y las interpretaciones críticas para usar el film directamente como un instrumento de transformación revolucionaria. De todos modos, es cierto, ambas propuestas cinematográficas coinciden en sus postulados básicos y comparten una misma metodología crítica que consiste en desmontar el discurso de la dominación para dejar al descubierto su falsedad. En un diálogo que mantuvieron Godard y Solanas a propósito de La hora de los hornos, las coincidencias son notorias. Ante la pregunta por los deberes del cineasta revolucionario, sus respuestas son variaciones de una misma actitud. Solanas dice que hay que «utilizar el cine como un arma o un fusil, convertir la obra misma en un hecho, en un acto, en una acción revolucionaria» y Godard sostiene que hay que «hacer menos films y ser más militante» ${ }^{10}$.

Cine realizado por grupos-guerrilla (Godard, incluso, prefiere hablar de «células» operativas porque le parece una terminología más política), que atacan directamente al corazón del individualismo burgués. Los equipos de cineastas militantes constituyen un estadio superador del cineasta auteur que expresaba una cosmovisión singular a través de su obra. Esa alternativa que Solanas y Getino llaman segundo cine nunca dejó de ser un intento reformista:

La virulencia, el inconformismo, la simple rebeldía, la insatisfacción, son productos que se agregan al mercado de compra y venta capitalistas, objetos de consumo. Sobre todo en una situación donde la burguesía necesita incluso una dosis más o menos cotidiana de shock y elementos excitantes de violencia controlada [...]. Todas estas alternativas 'progresistas', al carecer de una conciencia de la 
instrumentalización de lo nuestro para nuestra liberación concreta, al carecer en suma de politización, pasan a convertirse en el ala izquierda del sistema, sirviendo al mejoramiento de sus productos culturales. ${ }^{11}$ había tenido la pretensión de desbordar los límites del arte burgués. Su innovación había consistido en reclamar un cierto estatuto artístico para las películas; pero su ruptura, que había tenido lugar dentro de las rigurosas coordenadas de un discurso modernista, había resultado más bien moderada y ya había perdido eficacia. Para Torre Nilsson y sus colegas, la autonomía del arte no estaba puesta en cuestión, así como tampoco se interrogaba a los films sobre su eficacia más allá de la pantalla. El argumento de Solanas y Getino parece confrontar con otro tipo de experiencia: la provocación contracultural asociada a las actividades del Instituto Torcuato Di Tella y al emergente movimiento de cine underground. Cuando no se inscriben dentro de un programa revolucionario, la rebeldía, el inconformismo, la irreverencia acaban como un capricho pequeño burgués. ¿Hasta qué punto una vanguardia despolitizada cumple con el objetivo de cuestionar al sistema?

\section{IV}

Players vs. Ángeles caídos (Alberto Fischerman, 1969), cuyo rodaje coincide con la finalización de La hora de los hornos, es la película que sirve de modelo a ese cine underground: a partir de una lectura muy libre de La tempestad, de William Shakespeare, Fischerman reflexiona de manera lúdica sobre la creación artística y sobre las relaciones de poder entre el director y los actores, en un medio como el cine caracterizado por su modalidad de colaboración colectiva. La hipótesis de Fischerman es que, en el cine, cualquier margen de libertad creadora acaba inevitablemente sometido (expropiado, avasallado, reprimido, traicionado) por la voluntad tiránica del director.

Eso es lo que escribió sobre su propio film:

The Players vs. Angeles caídos. Discurso explícito sobre el actor quien, en sus improvisaciones, cree ejercer una libertad que el montaje castrador hará aparecer como ilusoria. Happening pesimista. Obvia referencia al Mayo de 1968, que se estaba desarrollando al mismo tiempo que la filmación, en las calles francesas. Ultima película que se filmó en los estudios Lumiton, la Isla de la Tempestad, el espacio escénico predestinado. El Gran Teatro del Mundo. Próspero, el demiurgo, el padre de Miranda, en suma, el director ausente, omnipresente. Grupos rivales de actores-fantasmas disputándose la propiedad del estudio y de la emulsión. ${ }^{12}$

Frente a la disolución del autor en un colectivo de trabajo, tal como sucede en el Grupo Cine Liberación, Fischerman rescata esa figura inspiradora como una fuente de sentido muy voluble, caprichosa, impredecible. Cada película es única y singular porque depende del temperamento siempre cambiante del director que pasa a ocupar el lugar de un oráculo o un hechicero. Frente al concepto tradicional de la obra como resultado de una planificación rigurosa, el happening, la performance y en general las formas del arte de acción ofrecen, a fines de los 60, un modelo novedoso dominado por el azar o lo aleatorio. Pero justamente por eso, The Players vs. Ángeles caídos descansa enteramente sobre las habilidades del director para encauzar la espontaneidad, la improvisación, lo imprevisto. Puesto que la película pretende, al fin y al cabo, constituirse como obra, esa voluntad hace que la figura del cineasta cobre un valor aun más determinante. Como si fuera una 
inspiración milagrosa -que no puede circunscribirse, anticiparse, sistematizarse-, el director es la única garantía de sentido.

Solanas y Getino dirían que en la propuesta de The Players vs. Ángeles caídos se explicita su propio fracaso: en los términos planteados por el director, cualquier intento de rebeldía termina neutralizado por la institución. Pero en realidad Fischerman se desliza por las superficies más disímiles, como si todas pertenecieran gozosamente al territorio unificado de lo contemporáneo: el cine de Godard y de Chitilova, las experiencias teatrales de Alberto Ure, los experimentos con alucinógenos en la clínica de Fontana, el Living Theater, las reflexiones de Oscar Masotta sobre el Pop, el existencialismo de Sartre, las minifaldas de Mary Quant. Lo que le interesa a Fischerman es el punto donde todas esas experiencias se intersectan, colisionan, intercambian y se confunden. La heterogeneidad de materiales no sirve para comunicar un mensaje unívoco sino, más bien, para desestabilizar la percepción. Por eso, los mundos de la publicidad y de los mass media no son presentados como un discurso diabólico. La mirada nunca olvida la parodia $\mathrm{y}$, por lo tanto, siempre resulta desacralizadora: posee esa ambivalencia tan propia del Pop, donde no es posible discernir si se trata de un cuestionamiento o de una celebración.

21 Lo que resulta curioso es que tanto la melancolía lúdica de Fischerman como el impulso sacrificial de Solanas al servicio de la eficacia revolucionaria se superponen sobre un vector de demolición. Acaso porque un campo arrasado puede ser una despedida y una promesa a la vez. The Players vs. Ángeles caídos y La hora de los hornos pertenecen al mismo horizonte cultural de finales de los años 60: allí donde los soportes, los formatos y los estilos tradicionales se han puesto en cuestión; donde la pureza de la obra ha sido reemplazada por lo heterogéneo, los materiales no convencionales y el collage; donde las vanguardias se mezclan con la comunicación de masas. Es probable que en ningún otro momento, ni antes ni después, los vínculos entre arte y publicidad hayan sido tan estrechos: gran circulación entre ambas esferas, múltiples intercambios y, a veces, cierta confusión sobre sus diferentes propósitos. Tanto Solanas como Fischerman trabajan en la realización de cortos publicitarios para la televisión y conocen bien los puentes que conectan los saberes del arte con las habilidades de la comunicación; sin embargo, los modos de circular por esos pasadizos son completamente opuestos en uno y en otro. Solanas utiliza el lenguaje publicitario para atacar al neocolonialismo y a la sociedad de consumo. Se trata de mostrar esa relación oculta entre realidades estrictamente conectadas (la riqueza de unos pocos es consecuencia de la pobreza de muchos) que los medios de comunicación se empeñan en presentar como si fueran dos universos separados y distantes. De esta manera, la publicidad capitalista puede ser redimida mediante su conversión en propaganda política. Del advertising al agitprop, lo que cambia no es la estrategia sino el contenido ideológico del mensaje. Para Fischerman, en cambio, el discurso de la publicidad forma parte de un continuo sobre el cual se asienta la cultura contemporánea: las vanguardias, los alucinógenos, la contracultura juvenil, la psicodelia, el rock, el comic, la televisión, la moda. Del advertising al Pop Art, la intensidad de su discurso estético consiste en una fusión de lo heterogéneo donde la fascinación y la ironía se implican mutuamente ${ }^{13}$.

Del viejo auteur al creativo (en el sentido publicitario) o el militante (en el sentido político) y de la antigua noción de obra al cine-happening o el film acto. Puesto que la noción de autor es correlativa de la noción de obra, cuestionar uno de esos términos supone necesariamente poner en cuestión al otro. De una u otra manera, estas películas se contaminan con las distintas formas del arte de acción y, por lo tanto, avanzan en la 
misma dirección que muchos escritores y artistas plásticos del período. En la Argentina, ese itinerario de desmaterialización se acelera a partir del golpe de Estado de 1966, aunque tampoco habría que reducir esas mutaciones estéticas a un simple derivado de los procesos políticos ${ }^{14}$. Se trata, más bien, de una lógica o un principio general de radicalización que rige a todas la manifestaciones culturales de ese momento. Así como las propuestas artísticas sirven cada vez más a los objetivos revolucionarios de la militancia, de la misma manera la militancia contribuye a la radicalización de las propuestas artísticas (las vuelve más irrecuperables por la institución, más irredimibles, más irreductibles). El arte y la política convergen en ese proceso para cumplir el sueño de toda vanguardia: la fusión entre estética y vida. Es, obviamente, un movimiento peligroso porque cuanto más lejos procura avanzar la obra, tanto más se acerca -como diría Foucault- a ese «infinito de su centro» donde ya no podría hacer pie y se hundiría calcinada.

\section{V}

A propósito de la revuelta popular que tuvo lugar en la ciudad de Córdoba el 29 de mayo de 1969, Altamirano se pregunta: « ¿No hubo un momento, un tiempo, en que la significación del cordobazo se mantuvo flotante y libre, en que la brecha que había producido en el continuo histórico siguió abierta, en que la expectativa de lo nuevo predominó sobre lo ya pensado y lo ya visto? $\aleph^{15}$. Aunque durará poco, este final de década es, en un sentido amplio, un instante flotante y libre, donde todo está por suceder.

The Players vs. Ángeles caídos y La hora de los hornos ponen en escena ese momento de tensión, antes del clivaje que caracterizará a los años siguientes. Para Solanas, el cine se enfrenta a su última oportunidad de transformar el mundo: ése es el optimismo trágico que desborda la imagen final del Che Guevara muerto convocando a la revuelta y al sacrificio. Fischerman, en cambio, asiste por anticipado al fracaso de toda ilusión: la insinuación de una película libre, donde los actores y sus improvisaciones hubieran tomado el poder, se desvanece finalmente bajo el peso disciplinador del montaje y la tiranía del director. No hay optimismo aquí, pero tampoco tragedia; sólo un desencanto gozoso y leve. En estos lineamientos cinematográficos -tal como ha mostrado Sarlo-, la vanguardia estética y el radicalismo político conviven en una tensión que no podrá sostenerse mucho tiempo más ${ }^{16}$. En los años siguientes, ese vínculo será puesto en crisis de una manera violenta. Por eso, en un sentido profundo, 1969 resulta un fin y un comienzo.

Para Bataille, la poesía (en el sentido amplio de poiesis) es la expresión más elevada de un estado de pérdida: así entendida, toda intervención estética implica un gasto simbólico ${ }^{17}$. El arte sería, en sentido estricto, un acto de creación por medio del derroche. 0 como lo define Godard, en Histoire(s) du cinéma, citando a Malraux: «El arte, es decir, eso que renace de lo que fue quemado». 


\section{NOTAS}

1. Grupo Cine Liberación, «Significado de la aparición de los grandes temas nacionales en el cine llamado argentino», Cine del Tercer Mundo, año 1, no 1, octubre de 1969, pp. 82-83. 2. Mariano Mestman reconstruye las circunstancias en que fue exhibida La hora de los hornos tanto en Pesaro como en Cannes: «Postales del cine militante argentino en el mundo», Kilómetro 111 nº 2, 2001.

3. Citado en Ramón Font (comp.), Jean-Luc Godard y el Grupo Dziga Vertov: un nuevo cine político, Barcelona: Anagrama, 1976, pp. 171-172.

4. Stéphane Bouquet y Thierry Lounas, «Défense du cinéma. Entretien avec Jean-Henri Roger», Antoine de Baecque, Stéphane Bouquet y Emmanuel Burdeau, Cinéma 68, París: Cahiers du cinéma, 1998, p. 114. Véase también Kent Carroll, «Interview with the DzigaVertov Group», Evergreen Review n 83, octubre de 1970.

5. Glauber Rocha, «O ultimo escândalo de Godard», O século do cinema, Río de Janeiro: Alhambra, 1985, p. 241. Sobre las relaciones entre Godard y Rocha, véase Mateus Araújo Silva, «Godard, Glauber e o Vento do leste: alegoria de um (des)encontro», Devires, Belo Horizonte, vol. 4, nº 1, enero - junio de 2007. Y Sobre las discusiones entre Rocha y Solanas, véase Ignacio del Valle Dávila, Cámaras en trance. El Nuevo Cine Latinoamericano, un proyecto cinematográfico subcontinental, Santiago de Chile: Cuarto propio, 2014.

6. Fernando Solanas y Octavio Getino, «Hacia un tercer cine: apuntes y experiencias para el desarrollo de un cine de liberación en el tercer mundo", Cine, cultura y descolonización, Buenos Aires: Siglo XXI, 1973, p. 57.

7. Op. cit., pp. 132-133. Para una crítica a la noción de obra y de autor según Solanas, véase James Roy Macbean, «Fernando Solanas: An Interview», Film Quarterly, vol. 24, n 1, Autumn 1970.

8. En muchos de los films políticos que se realizan en la estela de La hora de los hornos (Ya es tiempo de violencia, Enrique Juárez, 1969 o Argentina, mayo de 1969: los caminos de la liberación, Grupo Realizadores de Mayo, 1969), el carácter colectivo o el escaso protagonismo del autor resulta más evidente. No sólo porque se trata de películas clandestinas (el film de Solanas también lo era) sino porque su valor instrumental reconoce un público muy específico y una finalidad concreta e inmediata. El film no habla para los espectadores sino que habla con ellos. Las imágenes no desbordan sobre sus interlocutores; más bien, son los interlocutores quienes se dejan representar por el film y luego se reconocen en las imágenes. La película es una interpósita persona. Si no importa quién habla es porque dice lo que cualquiera (cualquiera de los directores o cualquiera de los espectadores) podría decir. Se expresa como lo haría un delegado gremial: habla por todos. Es sólo un portavoz o un catalizador de los reclamos colectivos. El pluralis auctoris es aquí un modo de indicar que la película respresenta a determinados sectores del pueblo a quienes se convoca para participar en la lucha.

9. Martin Even, «Entrevista con Jean-Pierre Gorin», Le Monde, 27 de abril de 1972. Reproducida en Ramón Font (ed.), Jean-Luc Godard y el Grupo Dziga Vertov: un nuevo cine político, Barcelona: Anagrama, 1976, p. 178.

10. Jean-Luc Godard y Fernando Solanas, «Godard por Solanas, Solanas por Godard», Cine del Tercer Mundo n 1, Montevideo, octubre de 1969, p. 53. 
11. Fernando Solanas y Octavio Getino, «Hacia un tercer cine», op. cit., p. 63.

12. Alberto Fischerman, «Actor rebelado, actor revelado», Film no 2 , junio - julio de 1993, p. 32 .

13. Eso mismo podría decirse de las películas que comienzan a girar dentro de su órbita: Puntos suspensivos (Edgardo Cozarinsky, 1971), Opinaron, (Rafael Filippelli, 1971), Alianza para el progreso (Julio Ludueña, 1971), La familia unida esperando la llegada de Hallweyn (Miguel Bejo, 1971). He trabajado sobre Fischerman y esta red de cineastas en David Oubiña, El silencio y sus bordes. Modos de lo extremo en la literatura y el cine, Buenos Aires: FCE, 2011. Sobre las problemáticas relaciones entre el cine y el arte Pop a fines de la década, véase Edgardo Cozarinsky, «¿Hubo alguna vez un Pop-Cinema?», El cielo, año 1, no 3, noviembre-diciembre de 1969, cuya reflexión es contemporánea a los acontecimientos.

14. Sobre este proceso de desmaterialización, véase Ana Longoni y Mariano Mestman, Del Di Tella a Tucumán arde. Vanguardia artística y política en el 68 argentino, Buenos Aires: El cielo por asalto, 2000.

15. Carlos Altamirano, «Memoria del 69», Punto de vista. Revista de cultura $\mathrm{n}^{\circ} 49$, agosto de 1994, pp. 6-7.

16. Beatriz Sarlo, «La noche de las cámaras despiertas», La máquina cultural. Maestras, traductores y vanguardistas, Buenos Aires: Ariel, 1998.

17. Bataille, Georges, «La noción de gasto», La parte maldita, Barcelona: Icaria, 1987, p. 30.

\section{RESÚMENES}

A fines de los años 60, se publican en Francia “¿Qué es un autor?” (Foucault) y "La muerte del autor" (Barthes): en esos textos se cuestiona la noción de autoría tal como era entendida por la tradición clásica. En ese mismo momento, Jean-Luc Godard -que había roto con la Nouvelle vague y había fundado el Grupo Dziga Vertov- explora las posibilidades del cine como órgano de comunicación colectivo al margen de la categoría de auteur que habían impuesto los Cahiers du cinéma en los años 50. En la Argentina, 1969 es el año de The Players vs. Ángeles caídos, la ópera prima de Alberto Fischerman que rápidamente se convierte en un referente del movimiento underground. La película rivaliza con La hora de los hornos (1968, Fernando Solanas) que se proyecta clandestinamente y que critica fuertemente a las vanguardias despolitizadas. Estos dos films representan modelos diferentes para pensar la relación entre arte y política, pero también para analizar los cambios que atraviesa la categoría de autor cinematográfico.

Este ensayo se propone indagar sobre las diversas transformaciones de esa noción en las postrimerías de una década que se había caracterizado por poner en entredicho todas las certezas.

À la fin des années 1960 ils ont été publiés en France «Qu'est-ce qu'un auteur? " (Foucault) et «La mort de l'auteur» (Barthes). Dans ces textes on met en question la notion d'auteur tel quel elle a était compris par la tradition classique. À la même époque Jean-Luc Godard - qui venait de rompre avec la Nouvelle Vague et qui avait fondée le Groupe Dziga Vertov - explore les possibilités du cinéma en tant qu'agence de communication collective, au delà de la catégorie d'auteur imposée par Cahiers du Cinéma dans les années 1950. En Argentine 1969 est l'année de The Players vs. Ángeles caídos, premier film d'Alberto Fischerman qui vitement devient un protagoniste du 
mouvement underground. Le film rivalise avec La hora de los hornos (1968, Fernando Solanas) - film interdit et présenté en séances clandestins - où il y a une forte critique aux avant-gardes dépolitisées. Tous les deux films représentent différents modèles de penser le rapport entre art et politique, mais aussi ils montrent deux voies pour analyser les changements qui souffre la catégorie d'auteur cinématographique.

Cet essaie se propose d'explorer les différents transformations de cette notion à la fin d'une décennie caractérisé par mettre en question toutes les certitudes.

In the late sixties, two crucial texts come out in France: "What Is an Author?" (Foucault) and "The Death of the Author" (Barthes). In both essays the classical notion of authorship is put into question. At the same time, Jean-Luc Godard -who had already broken away from the Nouvelle Vague and had founded the Dziga Vertov Group- explores the possibilities of cinema understood as an apparatus for collective communication beyond the margins of the category of auteur imposed by the Cahiers du cinéma in the 50s. In Argentina, 1969 is the year of The Players vs. Ángeles caídos, Alberto Fischerman's first feature film that very quickly becomes a landmark for the underground movement. The film confronts with The Hour of the Furnaces (1968, Fernando Solanas) that is clandestinely shown and that strongly criticizes the apolitical avant-garde. These two films represent different ways of conceiving the relationship between art and politics, but also different ways of analyzing the transformations undergone by the film auteur category.

The goal of this essay is to interrogate the various changes experienced by the notion of authorship by the end of a decade characterized for the questioning of all certainties.

\section{ÍNDICE}

Mots-clés: auteur cinématographique, art et politique, cinéma militant, cinéma underground.

Palabras claves: autor cinematográfico, arte y política, cine militante, cine underground.

Keywords: Film Authorship, Art and Politics, Militant cinema, Underground Cinema.

\section{AUTOR}

\section{DAVID OUBIÑA}

CONICET - UBA

doubinia@retina.ar 